\title{
The Effect of Supplementary Shouting Technique on Muscle Activity to Rectus Abdominis and External Oblique During Crunch Exercise in Healthy Subjects
}

\author{
Chang-Yong Kim ${ }^{1}$, Hyeong-Dong Kim² \\ 'Department of Health Science, The Graduate School, Korea University; ${ }^{2}$ Department of Physical Therapy, College of Health Science, Korea \\ University, Seoul, Korea
}

Purpose: The purpose of this study was to examine the effects of a supplementary shouting technique on abdominal muscle activation to the rectus abdominis (RA) and external oblique (EO) muscles during performance of crunch exercise in healthy subjects.

Methods: Sixty-four subjects were randomly allocated to two groups, crunch exercise with shouting group (SG) and crunch exercise with non-shouting group (NSG), with 32 subjects in each group, respectively. The interventions were conducted over three trials in each group, and measurements were performed on each subject by one examiner in three trials. Muscle activation of RA and EO was evaluated using electromyography (EMG) during performance of crunch exercise with or without shouting.

Results: Our results showed a significantly greater increase in the EMG patterns of the RA and EO muscles during performance of crunch exercise in the SG compared to the NSG $(p<0.01)$.

Conclusion: These findings suggest that addition of the shouting technique during performance of crunch exercise, at the same time, would suggest positive evidence for improving activation of abdominal muscles.

Keywords: Abdominal muscle, Crunch exercise, Electromyography (EMG), Shouting

\section{서 론}

아침에 몸을 일으키는 단순한 동작에서부터 스포츠 경기를 비롯하 여 물건을 나르는 등의 근로 현장에 이르기까지 우리는 근력을 필요 로 하는 다양한 활동을 수행하며, 수행 과정 동안 종종 고함 소리를 들을 수 있다. 이와같이 일상생활을 하는 동안 의식 또는 무의식적으 로 외치는 고함 소리를 기합(shouting)이라고 하며, ${ }^{1}$ 무도를 수련할 때 나근력을 필요로 하는 운동 수행 시 집중력 향상이나 심리적으로 더 강하고 높은 근력을 발휘하고자 할 때 기합을 사용한다. ${ }^{2}$ 또한, 동양 학적 개념의 기합은 우리 몸 속에 의식적으로 사용하지 않는 잠재력 을 끌어올리는 다양한 방법 중 하나로 사용해 왔으며 더불어 오랜 세 월에 걸쳐 선조들의 무예 수련 과정 및 전쟁 등에서 아군의 사기를 북 돋아 주며 동시에 적의 사기를 낮추고 신경적, 정신적 자극에 의한 근 력 증대를 통하여 전투력을 증진시키는 등 매우 큰 역할을 해왔다.

이전의 기합과 관련한 선행연구에 보고된 바에 따르면, 기합이 얼
마나 더 많은 운동 뉴런(motor neuron)을 동원할 수 있는가를 알 수 있는 H-reflex 측정과 근육의 활성 정도를 근전도를 이용하여 최대 등 척성 수축력을 측정한 연구 결과에서 기합을 넣으면 운동 뉴런 흥분 성이 약 1.3 배 증가하였고, 또한 근력의 최대 등척성 수축력도 커졌다 고 보고하였으며1,3 무산소성 운동 시 기합 유형에 따른 근 파워를 분 석한 결과 대상자가 기합을 하지 않았을 때보다 측정자만 기합을 하 였을 때와 측정자 및 대상자 모두 기합을 하였을 때 최대 파워, 총 일 량, 평균 파워 변수에서 유의한 수준으로 높게 나타났고, ${ }^{4}$ 년 이상의 무도 수련자들에게 기합을 적용하였을 때 기합에 의한 등척성 근력 이 $15.14 \%$ 증가하였으며, 일반인 또한 $14.31 \%$ 증가하였다고 보고하였 다. ${ }^{1}$ 이와 같이 기합을 통한 근력 증진의 효과는 다양한 생활에 응용 및 연구되어 왔다.

크런치 운동(crunch exercise)은 제한된 장소에서 복부의 근력을 증 진시키기 위해 누구나 쉽게 수행할 수 있는 운동으로, ${ }^{5}$ 크런치 운동 시 복부 근육 중 주로 복직근(rectus abdominis)과 외복사근(external 
oblique)이 활성화 된다. ${ }^{6,7}$ 복부의 수직 방향으로 주행하는 복직근은 전 및 외측에 주행하는 복부 근육과 같이 복부 내 장기를 외부의 상 해나 손상으로부터 보호하고, 수축시 복압을 상승시키며, 몸통 운동 시 자세를 유지하는데 안정성을 제공한다. ${ }^{8,9}$ 또한 몸통의 외측(lateral)에서 내측(medial)으로 주행하는 외복사근은 몸통을 회전하는 데 강한 힘을 내주는 기능을 하며 몸통의 외적 안정성에 도움을 준다.9,10 이와 같이 복직근과 외복사근은 몸통의 자세유지에 관여하여 몸통 안정성을 갖게 하고 몸통의 굽힘(flexion)이나 돌림(rotation) 등 복부 운동 시 필요한 근력을 제공한다.

위의 선행 연구와 배경 지식에서 언급한 바와 같이 기합은 일상생 활 동작이나 운동 선수들의 경기력을 향상시키기 위해 부가적으로 사용되고 있다. 하지만 기합 적용의 효과에 대해 특정 복부 근육에 대한 근 활성도 측면의 정량적인 분석이 부족한 실정이며, 특히 임상 현장에서 복부 근력을 증진시키기 위한 치료적인 기법으로써 연구되 거나 제시되고 있지 않다.

따라서 본 연구에서는 정상인을 대상으로 복부의 근력을 향상시 키기 위해 사용되는 크런치 운동만을 적용하였을 때와 크런치 운동 과 기합을 동시에 적용하였을 때에 복부 근육인 복직근과 외복사근 의 근 활성도에 미치는 영향을 알아보고자 한다. 이 연구는 구체적으 로 다음의 문제를 해결하고자 복부의 근력을 향상시키기 위해 사용 되는 크런치 운동만을 적용하였을 때보다 기합을 동시에 적용하였 을 때에 복부 근육인 복직근과 외복사근의 근 활성도가 더욱 향상될 것이다라고 연구 가설을 설정하였다.

\section{연구방법}

\section{1. 연구대상}

본 연구의 대상은 서울 소재 4 년제 대학에 다니는 대학생들 중에서 20-30대 건강한 성인 64명(남자 34명, 여자 30명)을 표본으로 선정하 였고, 대상자들은 실험 전에 연구의 목적과 방법에 대해 충분히 설명 을 듣고 자발적으로 실험에 동의하였으며 실험과정은 생명윤리심의

Table 1. Demographic characteristics of the subjects

$(N=64)$

\begin{tabular}{lcccc}
\hline Characteristics & $\begin{array}{c}\text { SG } \\
\left(\mathrm{n}_{1}=32\right)\end{array}$ & $\begin{array}{c}\text { NSG } \\
\left(\mathrm{n}_{2}=32\right)\end{array}$ & $\chi^{2} / \mathrm{t}$ & $\mathrm{p}$-value \\
\hline Gender (Male/Female) $^{*}$ & $16 / 16$ & $18 / 14$ & 0.08 & 0.78 \\
Age (year) & $27.4 \pm 7.3$ & $26.5 \pm 6.5$ & 1.17 & 0.26 \\
Weight $(\mathrm{kg})$ & $65.4 \pm 9.0$ & $64.7 \pm 7.4$ & 0.23 & 0.72 \\
Height $(\mathrm{cm})$ & $166.9 \pm 10.2$ & $164.7 \pm 8.9$ & 0.43 & 0.67 \\
Body mass index $\left(\mathrm{kg} / \mathrm{m}^{2}\right)$ & $22.4 \pm 2.5$ & $21.9 \pm 3.3$ & 1.16 & 0.26 \\
Decibel $(\mathrm{dB})$ & $83.3 \pm 7.6$ & $82.2 \pm 6.8$ & 0.32 & 0.22 \\
\hline
\end{tabular}

Values are expressed as mean \pm standard deviation. SG, Shouting group; NSG, Non-shouting group.

*Values are numbers.
위원회의 심의를 거친 후 실시되었다. 표본 크기는 이전의 연구되어 온 수집된 자료를 근거로 추정되었고, ${ }^{3}$ General power analysis 프로그 램(GPower 3.1 $)^{11}$ 을 이용하여 0.85 통계학적 검증력(statistical power)을 얻기 위해 각 군의 최소 26명의 표본 크기(sample size)가 산출되었다. 위의 표본 크기 계산은 신뢰도 계수를 0.90 으로 가정하고, 두 군 사이 의 평균값을 비교하는 독립 $\mathrm{t}$ 검정에 기초하였다. 근전도에서 측정되 는 근 활성도의 측정방법을 향상시키기 위해 신체질량지수(body mass index, BMI)를 이용하여 계산된 점수가 18.5에서 24.9사이에 해 당되는 대상자로 선정하여 연부 조직의 동질성을 최대한 유지하였 다. ${ }^{12}$ 모든 대상자는 실험에 영향을 주는 신체적 결함이 없는 자로 선 정하였으며, 근골격계 및 신경계 관련 질환이 있는 자, 최근 3개월 동 안 요통을 경험한 자, 심각한 자세 기형이 있는 자는 연구 대상에서 제외하였다. 연구대상자의 일반적 특성은 Table 1과 같다.

\section{2. 실험방법}

1) 실험절차

본 연구의 전반적인 실험 절차는 Figure 1 과 같다. 본 연구에 참여한 64 명의 정상인에 대해 각각의 군을 의미하는 2 개의 카드가 포함되어 있는 상자에서 1 개의 카드를 뽑아서 이에 맞게 기합 적용 군과 기합 비적용 군에 각각 32 명씩 무작위 추출법을 사용하여 배정하였다. 연 구 결과의 신뢰성을 높이기 위하여 평가 및 자료 분석을 담당한 연구 자는 대상자들의 배정된 군을 알지 못하도록 하였다. 두 군 모두 복직 근과 외복사근을 활성화 시키기 위해 크런치 운동을 수행하도록 하 였다.5,13 대상자는 요추 전만이 적게 일어나도록 바로 누운 자세로 위

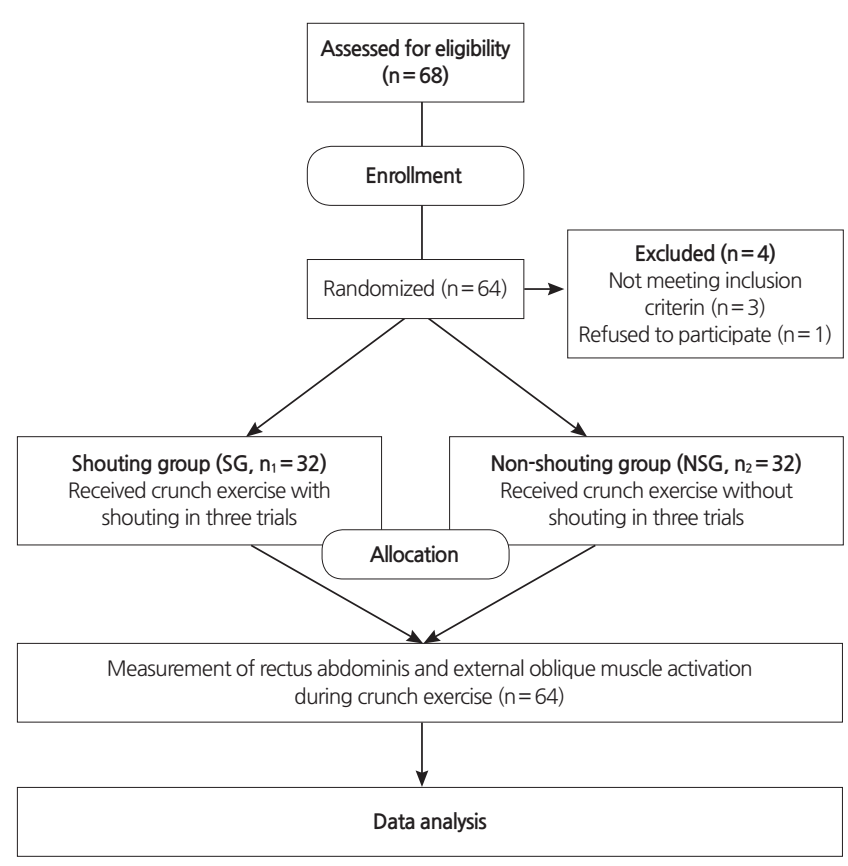

Figure 1. Procedures used in this study. 
치시키고, 고관절 굴곡근의 보상 작용을 미리 차단하기 위하여 무릎 아래에 베개를 받혀 다리가 이완되도록 하였다. 또한 대흥근(pectoralis major)의 보상작용이 일어나지 않도록 차단하기 위해 견갑골 밑을 수건으로 받쳐 주어 양쪽 어깨가 이완되도록 하였다.5,13 그리고 대상 자의 양 팔을 편 상태로 몸통의 면 위로 뻗게 하고, 견갑골의 위치를 최대한 외전 및 상방회전시켜 머리를 멀리 쳐다보듯이 들고 복직근 과 외복사근을 수축하도록 하였으며, 측정자의 '몸통을 들어 올리세 요라는 지시에 따라 체간을 들어 올린 후 유지 하세요라는 지시에 7 초간 유지하였다. 이때, 기합을 적용한 군에서는 7초간 유지하는 동 안 3-5초에 기합을 적용할 수 있도록 기계음(beeper)으로 신호를 주었 고, 기합을 적용하지 않는 군에서는 7초간 크런치 운동을 유지하도록 하였다.

\section{2) 측정도구 및 측정방법}

(1) 근 활성도 측정

복직근과 외복사근의 근 활성도 측정을 위해 근전도 장비 TELEMYO DTS (Noraxon USA Inc., Scottsdale AZ, USA)를 사용하였고(Figure $2 \mathrm{~A}$ ), 수집된 자료의 개인용 컴퓨터와 연동하여 근전도 소프트웨 어 MR-XP Master Edition version 1.07 (Noraxon USA Inc., Scottsdale AZ, USA)을 사용하였다. 근전도 신호의 표본 추출률(sampling rate)은 $1,024 \mathrm{~Hz}$ 로 하였으며, 잡음을 제거하기 위해 대역통과(band-pass) 필 터는 20-300 Hz, 대역정지(band-stop) 필터는 $60 \mathrm{~Hz}$ 로 처리하였다. 근 육의 근전도 신호를 완파 정류(full-wave rectification) 후 실효치 진폭 (root mean square, RMS)으로 처리하였다. 표면 근전도 신호에 대한 피 부 저항을 감소시키기 위해 털을 제거하고 사포로 피부를 3-4회 문질 러 각질을 제거하였으며, 의료용 알코올 솜으로 닦은 후 전극 배치를 하였다. 각 전극간 거리는 $2 \mathrm{~cm}$ 로 하였고, 전극의 부착부위는 다음과 같다. 외복사근은 장골능과 늑골 사이에서 평행하게 사선으로 주행
하므로 전상장골극(anterior superior iliac spine) 위 복직근 외측에 있 는 부분으로 배꼽에서 외측으로 $15 \mathrm{~cm}$ 지점에 부착하였고, ${ }^{14,15}$ 복직 근은 검상돌기 아래의 근육팽부의 중앙 부위인 배꼽 위 $3 \mathrm{~cm}$ 지점에 부착하였다. ${ }^{15,16}$

기합 적용 여부에 따른 복직근과 외복사근의 근육 활성도 측정은 크런치 운동 시 7 초간 유지하며 얻어진 근전도 신호 중 앞과 뒤 1 초를 제외한 5 초간의 측정치 값을 사용하며, 총 3 회 측정하여 그 평균값을 이용하였다. 정규화(normalization) 과정의 참고값은 도수의 저항을 준 상태의 최대 수의적 등척성 수축(maximal voluntary isometric contraction, MVIC) 시 각 근육의 최대 근 활성도를 5 초 동안 유지, 3 회 반 복측정하였다. ${ }^{5} 5$ 초 동안의 자료 값을 RMS로 처리한 후 처음과 마지 막 1 초를 제외한 3 초 동안의 평균 근전도 신호량을 $100 \% \mathrm{MVIC}$ 로 사 용하였다. 최대 수의적 수축 측정 동작은 각 근육별 움직임의 반대측 으로 도수 저항을 준 상태에서 복직근은 체간의 굴곡, 외복사근은 체 간을 굴곡하면서 반대측으로 체간을 회전하여 측정하였다. ${ }^{15,17}$

\section{(2) 소음측정기}

크런치 운동하는 동안 기합 적용에 사용된 데시벨(decibel, dB)을 일 정하게 측정하기 위해 Digital sound level meter (BE051, (주)라이트컴, Seoul, Korea) (Figure 2B)를 사용하였고, 대상자로부터 $75 \mathrm{~cm}$ 떨어진 거리에서 75-90 dB로 일정하게 기합을 하도록 유지하였다. ${ }^{18}$

\section{3) 자료분석 및 통계방법}

본 연구에서의 자료 통계처리는 상용 통계프로그램인 윈도우용 PASW Statistics 18.0 프로그램을 사용하였다. 측정값은 평균과 표준 편차로 표시되었다. 본 연구에 수집된 표본들이 정규성 검정 $(\mathrm{Kol}-$ mogorov-Smirnov test)에서 정규 분포 곡선을 띠고 있으므로, 모수 검 정법을 사용하였다. 연구 대상자들의 일반적 특성 중 성별은 CROSS-
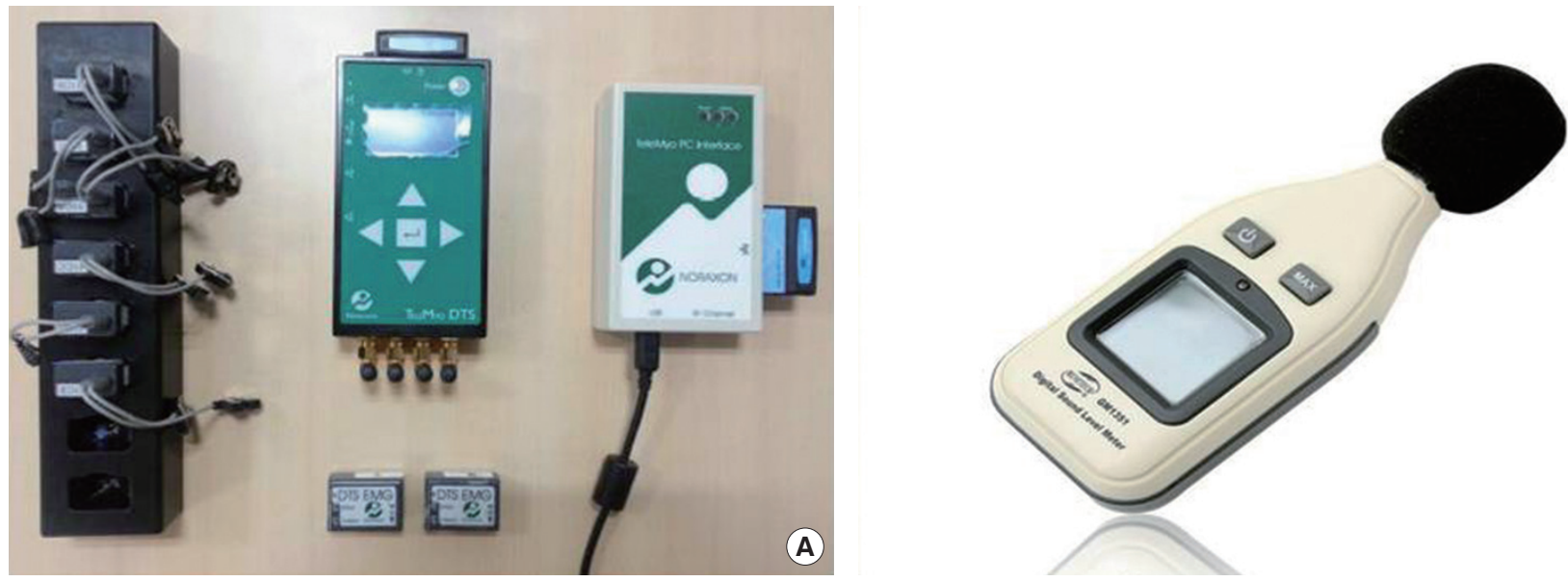

Figure 2. The surface electromyography electrode (A) and digital sound level meter (B) used in this study. 
$\mathrm{TAB}$ 의 $\chi^{2}$ (Chi-Square test) 검정을 실시하였고, 연령, 신장, 체중, 신체질 량지수, 그리고 데시벨와 같은 연구 대상자의 일반적 특성과 두 집단 사이의 기합 적용 여부에 따른 복직근과 외복사근의 근활성도의 차 이를 규명하기 위해 독립 표본 $\mathrm{t}$ 검정을 실시하였으며, 가설 수락을 위 한 유의수준은 0.05 로 설정하였다.

\section{결 과}

\section{1. 기합 적용 유무에 따른 각 군의 복직근과 외복사근의 근 활성도 비교}

복직근과 외복사근에 대한 기합 적용 군과 비적용 군의 평균과 표준 편차 및 이들 값에 대한 독립 $\mathrm{t}$ 검정 결과는 다음과 같다(Table 2). 크런

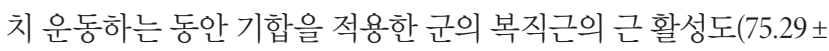
$13.14)$ 가 기합을 적용하지 않는 군보다(62.38 17.09$)$ 통계학적으로 유 의하게 증가하였고 $(\mathrm{t}=5.76, \mathrm{p}<0.01$ ) (Figure 3$)$, 크런치 운동하는 동안 기합을 적용한 군의 외복사근의 근 활성도가 $(86.29 \pm 20.72)$ 기합을 적 용하지 않는 군보다 $(70.87 \pm 16.55)$ 통계학적으로 유의하게 증가하였다 $(\mathrm{t}=4.17, \mathrm{p}<0.01)$ (Figure 3$)$.

\section{고 찰}

우리는 일상 생활 중 상당한 근력을 요구하는 동작이나 운동선수들 의 경기력을 향상시키기 위해 의식 또는 무의식적으로 기합을 사용 함으로써, 신경적 및 정신적 자극에 의한 근력을 증대시킨다.1,3,4 그러 나 임상에서 치료적인 기법으로써의 기합에 관한 연구는 미비한 실 정이며, 더불어 특정 복부 근육에 대한 근 활성도 측면에서 기합 적용 의 효과에 대한 명확한 증거를 밝힌 연구도 제시되지 않았다. 이에 본 연구는 기합의 적용이 정상인의 복부 근 활성도에 어떤 영향을 미치 는지에 대한 정량적 자료를 얻고자 건강한 성인 64명을 대상으로 근 전도 장비를 이용하여 기합 적용 유무에 따른 복부 근육의 활성도를 측정하였다. 본 연구 결과, 기합을 적용한 군이 기합을 적용하지 않은 군보다 복직근과 외복사근의 근 활성도가 통계학적으로 유의하게 증 가하였다.

Table 2. Comparison of EMG activities to the rectus abdominis and external oblique muscles between the shouting group (SG) and nonshouting group (NSG)

$(\mathrm{N}=64)$

\begin{tabular}{lcccc}
\hline$\%$ MVIC & $\begin{array}{c}\text { SG } \\
\left(n_{1}=32\right)\end{array}$ & $\begin{array}{c}\text { NSG } \\
\left(n_{2}=32\right)\end{array}$ & $t$ & $p$-value \\
\hline Rectus abdominis & $75.29 \pm 13.14$ & $62.38 \pm 17.09$ & 5.76 & 0.001 \\
External oblique & $86.29 \pm 20.72$ & $70.87 \pm 16.55$ & 4.17 & 0.004 \\
\hline
\end{tabular}

Values are expressed as mean \pm standard deviation.

MVIC, Maximal voluntary isometric contraction.
본 연구에서 크런치 운동하는 동안 적용하는 기합을 일정하게 정 량화하기 위해서 소리의 상대적인 크기를 나타내는 데시벨을 측정하 였고, 데시벨 값을 선정함에 있어서 Chig과 john ${ }^{18}$ 의 연구와 동일하게 적용하였다. 즉, 연구에 참여한 대상자로부터 $75 \mathrm{~cm}$ 떨어진 곳에서 데 시벨을 측정했을 때 평균 75-90 dB로 일정하게 유지한 상태에서 크런 치 운동을 수행하도록 하였다. 또한, 복부의 복직근과 외복사근을 활 성화시켜 활성화된 복부근육들의 활성도를 측정하기 위해 이전의 연 구에서 사용된 크런치 운동을 적용하였고, ${ }^{5,13}$ 크런치 운동 시 고관절 굴곡근의 대상작용을 최대한 차단하기 위해 대상자 무릎 아래에 베 개를 받혀 다리가 이완되도록 하였으며, 대흥근의 대상 작용을 차단 하기 위해 대상자 견갑골 밑에 수건으로 받쳐 주어 양쪽 어깨가 이완 되도록 하였다. 본 논문에 적용한 크런치 운동은 주로 복직근과 외복 사근이 활성화된다는 선행연구6,7를 기반으로 크런치 운동 시 기합 적 용 유무에 따라 측정 근육군을 복직근과 외복사근으로 제한하였다.

체간의 근육들은 척추 움직임이나 자세, 안정성에 있어 중요한 역 할을 한다. 기능적인 관점에서 볼 때, 체간 근육은 대근육(global muscle)과 소근육(local muscle)로 분류되는데, ${ }^{19}$ 본 연구의 측정 근육군으 로 선택된 복직근과 외복사근은 대근육으로 인체 내에서 토크를 발 생시키고 흉곽과 골반 사이에 직접적으로 부하를 전달한다. ${ }^{20}$ 특히, 외복사근은 근육 내 근전도나 표면 근전도 장비를 통해 체간 축 회전 에 있어 중요한 역할을 하는 것으로 알려져 있으며 ${ }^{19}$ 복직근과 함께 몸 전체가 움직일 때나 자세 적응 동안에 요추의 안정성과 연관이 있 다. ${ }^{21,22}$ 그뿐만 아니라, 본 연구에서는 표면근전도 시스템으로 측정가 능한 체간 전내측 및 외측에 위치하는 외복사근과 복직근을 측정 대 상으로 하여 체지방의 오염 요인을 최소화하고 근육 성질의 동질성 을 유지하기 위해 체질량지수 ${ }^{12}$ 를 기준으로 한 정상인 64명을 연구대 상으로 국한하였다.

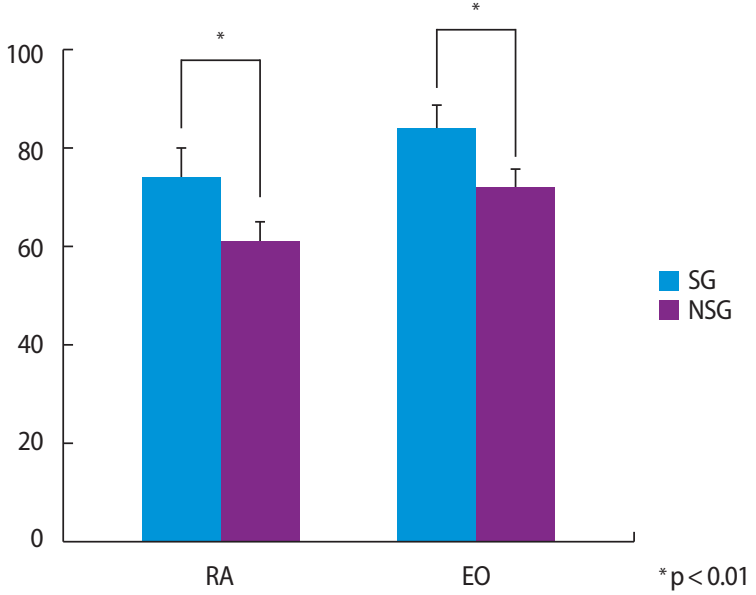

Figure 3. The comparison of EMG activation to the rectus abdominis (RA) and external oblique (EO) muscles between the shouting group (SG) and non-shouting group (NSG). 
본 연구에서 기합 적용 유무에 따른 외복사근과 복직근의 근 활성 도 비교 결과를 보면 기합 적용이 복직근과 외복사근의 활성도 향상 에 영향을 미쳤음을 확인할 수 있었다. 이는 이전의 선행 연구 결과와 일치하며, ${ }^{3,23,24}$ 기합 적용 시 두 근육의 근 활성도 수준(level) 증대에 긍정적인 영향을 미침으로써 더 많은 근육을 동원할수 있게 되어 근 육의 힘이 크게 발휘되는데 영향을 미치는 것으로 사료된다. 우리가 운동을 할 때 뇌에 운동하라는 명령은 전기적 신호로 바뀌어 신경을 통해 우리 몸 각 기관을 통해 전달되는데, 이때 기합을 지르면 우리 몸은 흥분 상태가 되고, 신경 내 운동 뉴런 역시 흥분하게 되어 움직 이라는 신경 신호가 더 빨리 그리고 더 많이 각 근육에 전달되며, 이 러한 원리로 더 큰 힘을 내게 되는 것이다. 즉, 기합을 넣으면 신경 전 달 속도가 빨라지면서 그 빈도수가 높아지고, 빈도수가 높아지면 결 국 더 많은 근 섬유를 동원하게 되는 것이다.1,3

이와 같이 복직근과 외복사근의 근 활성도 증가는 자세를 유지하 고, 기능적 움직임을 수행하는데 필수적 요소인 체간의 외적 안정화 (extrinsic stability)를 강화시킬 수 있으며 이는 $\mathrm{Lim}^{25}$ 의 연구에서와 같 이 복근 강화를 통해 증가시킬 수 있다. 결과적으로 기합을 통한 체 간 중심화 근육(core muscle)의 강화로 이끌어 낼 수 있는데, 중심화 근육이란 인체의 중심을 뜻하는 말로써 움직임을 위한 힘을 발생시 키는 힘의 원천이며, 사지의 움직임을 안정시킴으로써 자세 균형에 중심적인 역할을 한다. ${ }^{26,27}$ 중심화 근육의 중요성에 대해서는 이전의 연구 결과를 통해 입증되었고, ${ }^{27-30}$ 본 연구에서 중재로 다루었던 기합 을 이용해 복부 근육의 근 활성도 향상을 도출한 결과가 간접적으로 중심화근육의 안정화를 이끌어 낼 수 있다는 점이 본 연구에서 얻을 수 있는 긍정적인 부분이었다. 하지만 Lee 등 ${ }^{31}$ 은 최대 호기를 통해 복 부의 4 가지 근육의 활성도가 상승한다고 보고하였는데, 본 연구에서 나타난 근 활성도의 증가의 원인이 기합으로 인한 증가인지, 기합을 하는 동안의 호기를 통한 증가인지에 대해서는 명확하지 않아 추후 이 점을 보완한 연구가 필요하다고 사료된다. 더불어, 기합은 심리적 으로 긍정적인 영향을 주어 집중력 향상과 더불어 잠재력을 끌어올 리는 효과가 발생함으로써 더 강한 근력을 이끌어 낸다.1,2 이를 본 연 구에서 도출된 결과와 함께 재고해보면, 임상에서 기합을 적용한 운 동법을 활용함으로써 근력강화와 더불어 치료에 집중을 하여 환자 안에 내재되어 있는 잠재력을 더욱 발휘할 수 있을 것으로 사료된다.

이상의 결과로 크런치 운동 시 기합을 함께 적용한 운동이 복부 근육의 활성도 증가에 긍정적인 영향을 미쳤다는 것을 알 수 있었다. 이러한 결과를 통하여 기합이 임상에서 근골격계 및 신경계 환자 치 료 시 다양한 운동 방법과 함께 부수적인 치료기법으로써 활용될 수 있을 것이라 사료된다. 하지만, 본 연구의 연구 결과를 설명하는 데 있 어서는 몇 가지 제한점이 존재한다. 첫째, 본 연구에 참여한 대상자는 특정 연령대인 20-30대 건강한 성인만을 대상으로 하여 진행되었다.
둘째, 기합과 함께 매우 다양한 운동 프로그램 적용 규례를 적용할 수 있는데, 본 연구에서 수행한 크런치 운동보다 더욱 다양한 적용규 례를 시행함으로써 기합이 근 활성도 향상에 미치는 최적의 효과를 규명해야 할 것이다. 셋째, 본 연구에서 측정된 근 활성도는 복직근과 외복사근에 한정하여 다양한 부위의 측정이 이루어지지 못하였다 는 점이다. 따라서 임상적으로 더 유용한 자료가 되기 위해서는 다른 근육들에 대한 연구와 더불어 다양한 연령대 및 다양한 형태의 체간 불안정성을 가진 대상자들을 포함한 추후 연구가 이루어져야 할 것 이다.

\section{REFERENCES}

1. Kang KH, Yun JK. The effects of shouting on motor neural adaptation and maximum isometric contraction. Korean Journal of Sport Science. 2001;12(4):85-93.

2. Kim LS. What does Ki-hap (shout) mean in oriental martial arts. Korean Journal of Physical Eduaction. 2004;43(3):41-5.

3. Jeong IS, Oh CH, Lee DJ, et al. A study on H-reflex change and MVIC change depending upon shouting type. Korean Journal of Sport Biomechanics. 2009;19(4):655-61.

4. Kim JM. Analysis of the capacity of anaerobic exercise, lactic acid and body surface temperatures according. Keimyung University. Dissertation of Master's Degree. 2011.

5. Kim KS. The effect of horse-back riding exercise equipment and bridging-crunch exercise on hemiplegic patient's balance. Daegu University. Dissertation of Master's Degree. 2011.

6. Park JH, Jeong JH, Kim DS, et al. The effects of different sit-up bench angles on trunk and leg muscle activity. Korean Journal of Physical Education. 2013;52(6):563-72.

7. Hong SH, Kim HC, Kil JH. Comparing the activity of abdominal muscles (URA, LRA, RF) during three types of exercise. Health \& Sports Medicine. 2006;8(1):1-9.

8. Kim SY, Kim NS. Effects of Mulligan's mobilization with sustained natural apophyseal glides on the paraspinal muscle activity of subjects with chronic low back pain. J Kor Phys Ther. 2013;25(1):10-5.

9. Song HS. Know your core muscles correctly. Sports Science. 2009;109 (1):29-37.

10. Lee HO. Activation of trunk muscles during stabilization exercises in four-point kneeling. J Kor Phys Ther. 2010;22(5):33-8.

11. Faul F, Erdfelder E, Lang AG, et al. $G^{\star}$ Power 3: A flexible statistical power analysis program for the social, behavioral, and biomedical sciences. Behav Res Methods. 2007;39(2):175-91.

12. John EK, Beith ID. Can activity within the external abdominal oblique be measured using real-time ultrasound imaging? Clin Biomech (Bristol, Avon). 2007;22(9):972-9.

13. Oh KB. The Effect of core stability training on postural control and activity of daily living of stroke patients. Dankook University. Dissertation of Master's Degree. 2005.

14. Cram JR, Kasman GS, Holtz J. Introduction to surface electromyography. Maryland, Aspen Publishers Inc, 1998:360-374.

15. Kim SH, Lee JI. Comparison of trunk muscle activity during static 
standing position and standing position on therapeutic climbing wall. J Kor Phys Ther. 2014;26(1):27-32.

16. Ng JK, Kippers V, Richardson CA. Muscle fibre orientation of abdominal muscles and suggested surface EMG electrode positions. Electromyogr Clin Neurophysiol. 1998;38(1):51-8.

17. Hislop HJ, Montgomery J, Connolly B. Daniels and worthingham's muscle testing: Techniques of manual examination. 6th ed. Philadelphia, PA, W.B. Saunders Co, 2003:35-48.

18. Chi zhang, John HL. Analysis and classification of speech Mode: whisperd through shouted. 8th Annual Conference of the International Speech Communication Association, Interspeech, 2007.

19. Bergmark A. Stability of the lumbar spine: A study in mechanical engineering. Acta Orthop Scand Suppl. 1989;230:1-54.

20. Kim CY, Choi JD, Kim SY, et al. Reliability and validity of ultrasound Imaging and sEMG Measurement to external abdominal oblique and lumbar multifidus muscles. Phys Ther Korea. 2011;18(1);37-46.

21. Behm DG, Anderson K, Cuunew RS. Muscle force and activation under stable and unstable conditions. J Strength Cond Res. 2002;16(3):416-22.

22. McGill SM. Low back stability: from formal description to issues for performance and rehabilitation. Exerc Sport Sci Rev. 2001;29(1):26-31.

23. Bandy WD, Lovelace-Chandler V, Bandy B, et al. Adaptation of skeletal muscle to resistance training. J Orthop Sports Phys Ther. 1990;12(6):
248-55.

24. McComas A. Human neuromuscular adaptation that accompany changes in activity. Med Sci Sports Exerc. 1994;26(12);1498-509.

25. Lim JS. The influence of foot pressure and balance core-stabilization Exercise in stroke. Daegu University. Dissertation of Master's Degree. 2009.

26. Lee CY, Lee SK. A study of core exercise for sports injury prevention and athletic performance of ice hockey players. Journal of coaching development. 2010;12(3):155-62.

27. Kim HR, Kim YS. The effects of spinal stabilization exerciseusing gravity on patients with degenerative disc disease. J Kor Phys Ther. 2008; 20(1):23-31.

28. Akuthota V, Nadler SF. Core strenthening. Arch Phys Med Rehabil. 2004;85(1):86-92.

29. Kibler WB, Press J, Sciascia A. The role of core stability in athletic function. Sports Med. 2006;36(3):189-98.

30. Shim HB, Cho HY, Choi WH. Effects of the trunk stabilization exercise on muscle activity in lumbar region and balance in the patients with hemiplegia. J Kor Phys Ther. 2014;26(1):33-40.

31. Lee GW, Yoon TL, Kim KS, et al. EMG activity of abdominal muscles during lumbopelvic stabilization exercises. Phys Ther Korea. 2014; 21(2);1-7. 